\title{
HANNAH ARENDT E O DIREITO (PARTE II): $O$ OUTLAW E O DIREITO A TER DIREITOS*
}

\author{
Odilio Alves Aguiar** \\ https://orcid.org/0000-0002-7767-1932 \\ odilio@ufc.br
}

RESUMO O artigo visa relacionar a tese da centralidade do outlaw, para se pensar o direito, em Hannah Arendt, com a sua compreensão do direito como "direito a ter direitos", esboçada em "Origens do totalitarismo". Partindo da desintegração europeia no início do século XX e do surgimento do outlaw contemporâneo, o refugiado, refletiremos sobre o sentido do princípio da legalidade, sua relação, em Arendt, com a plural condição humana e o mundo comum. Mostraremos como estão contidos, na obra mencionada, elementos para uma articulação inicial entre a ideia do direito como "direito a ter direitos" $e$ uma teoria da cidadania na pensadora judia-alemã.

Palavras-chave Direito, refugiados, legalidade, pluralidade, cidadania.

ABSTRACT This article aims to relate the thesis of the centrality of the outlaw to think of Law, in Hannah Arendt with her understanding of Law as "right to have rights" drafted in Origins of totalitarianism. Starting from the European disintegration in the early twentieth century and the emergence of the contemporary outlaw, the refugee, we will reflect on the meaning of the principle of legality, its relationship, in Arendt, with a plural human condition and the common world. We will show how there are elements contained, in the

* Artigo submetido em 12/04/2018 e aprovado em 03/07/2018.

** Universidade Federal do Ceará - UFC. Fortaleza, CE, Brasil. 
work mentioned, for an initial articulation between an idea of law as "right to have rights" and a theory of citizenship in the Jewish-German thinker.

Keywords Law, refugee, legality, plurality, citizenship.

Nosso intento, no presente ensaio, é desenvolver parcialmente uma hipótese que apresentamos propedeuticamente em artigo anterior, publicado no $\mathrm{n}^{\circ} 18$ da Argumentos - Revista de Filosofia da Universidade Federal do Ceará, no qual esboçamos a ideia de que o refugiado constitui-se no paradigma a partir do qual Hannah Arendt pensa o direito. ${ }^{1}$ Significa que há, na obra de Hannah Arendt, um conjunto de textos nos quais a problemática do outlaw atravessa e autoriza o reconhecimento de certo padrão na abordagem da lei e do direito. ${ }^{2}$ Tais textos cobrem um arco que vai da década de 1940, como, por exemplo, "A questão das minorias", "Nós, refugiados", "O judeu como pária”, passando pelo tema do direito a ter direitos, da lei, do poder, da promessa, do julgamento e da constituição, até os escritos do final da sua carreira, na década de 1970, como "A desobediência civil". No presente texto, iremos cotejar o tema paradigmático dos refugiados com a proposta arendtiana do direito como "direito a ter direitos".

Inicialmente é importante realçar que o parti pris da autora não é o da Filosofia do direito, um sistema ou uma perspectiva jurídica específica. As questões jurídicas em Arendt não aparecem fechadas em si mesmas. Quando o tema do direito comparece na sua obra, não emerge de uma preocupação em resolver os dilemas inerentes ao problema da fundamentação teórica do direito. Sua reflexão, nesse campo, aparece em razão de circunstâncias difíceis,

1 Entendemos paradigmático em contraposição a apodigmático. O para (ாара) de paradigmático é uma partícula que no grego indica semelhança, proximidade entre ideias, coisas, pessoas e acontecimentos diferentes. Arendt utilizava, também, com esse mesmo sentido, o termo exemplum retirado da historiografia romana. Trata-se de um modo de compreender os eventos a partir de uma ação ou de um personagem específico que, mantendo sua especificidade, ilumina uma situação comum a vários eventos. $\mathrm{O}$ apo ( $\alpha$ rro) de apodigmático indica acima, distante. Uma ideia ou modelo apodigmático tem valor lógico, científico, axiomático, de verdade. O sentido analógico de paradigmático foi motivo da nossa escolha do termo paradigma e, assim, acreditamos manter fidelidade ao modo de Arendt compreender os acontecimentos histórico-sociais.

2 A tradução brasileira dos Escritos Judaicos, embora muito boa, peca por traduzir outlaw por fora da lei ou criminoso. Embora correta linguisticamente, não alcança o sentido conceitual do termo. O refugiado, o apátrida, o desnaturalizado ou as minorias nacionais vão muito além do criminoso e dos outlaws tradicionais: o proscrito, o excomungado, o banido, o exilado, o escravizado, o condenado ao ostracismo, uma vez que todos esses poderiam ainda ser acolhidos e ter algum lugar noutra parte do mundo. Já o outlaw contemporâneo não tem para onde ir, é descartado, seu destino é o extermínio. Além disso, não se trata de um indivíduo. O outlaw agora é um grupo ou etnia inocente, desprotegida e expulsa da lei, da sociedade e da humanidade. 
verdadeiras situações-limites, em que sua vida e o seu pensamento estavam enredados na Europa e na América. Destarte, poderíamos dizer que suas ideias são conduzidas no horizonte da Filosofia Política, ligadas às questões do poder, da cidadania, da ação política e, enfim, da organização do mundo comum. Por isso suas reflexões sobre essas questões distanciam-se, também, daquelas que reduzem o direito às práticas jurídicas, aos modos de organização e funcionamento das instituições jurídicas, dos procedimentos de sanção e aplicação da norma jurídica. Vale dizer, Arendt não é uma filósofa do direito nem pensadora das práticas jurídicas stricto sensu. Dessa forma, se há algo importante sobre o direito em Arendt, é por meio das suas tentativas conceituais de compreender as desafiantes questões políticas do seu tempo que podemos reconstituí-lo e explicitá-lo. O direito e as questões jurídicas remetem, na autora, aos problemas relacionados às possibilidades e limites das diversas e plurais formas de vida, ao mundo comum.

Essa é a razão de apontarmos a importância de captarmos o significado da figura do refugiado na autora. ${ }^{3} \mathrm{O}$ refugiado é o outro do mundo comum e simboliza a desintegração limítrofe desse mundo. Trata-se não só de uma categoria social problemática que emergiu no início do século $\mathrm{XX}$, mas de uma massa enorme da população que entrou na cena política e que provocou a alteração profunda da sua compreensão em termos social, jurídico e político. Como bem anotou Arendt:

Um refugiado costumava ser uma pessoa levada a buscar refúgio por causa de algum ato praticado ou opinião sustentada. Bem, é verdade que tivemos de buscar refúgio; mas não praticamos nenhum ato e a maioria de nós nunca sonhou em ter qualquer opinião política radical. Conosco o significado do termo "refugiado" mudou. Agora "refugiados" são aqueles de nós que foram tão infelizes a ponto de chegarem em um novo país sem recursos e terem de ser ajudados por comitês de refugiados (Arendt, 2016, p. 477).

O outlaw é um grupo ou etnia que reúne em si o desamparo por que estava passando um setor enorme da população humana e que prenunciava o perigo da descartabilidade e do extermínio de categorias humanas provenientes das propostas dos sistemas econômicos e políticos. Sobre eles, afirma Arendt:

3 Nossa abordagem diferencia-se das outras pela ênfase no refugiado. Quase todos os autores que abordaram o tema do direito em Arendt partem da desintegração do Estado-nação, mas não observam a centralidade e o caráter paradigmático do outlaw. Cf. Lafer, 1991; Volk, 2015; Gündogdu, 2011 e 2015; Goldoni e Mccorkindale, 2012; Benhabib, 2012. 
Uma vez fora do país de origem, permaneciam sem lar; quando deixavam o seu Estado, tornavam-se apátridas; quando perdiam os seus direitos humanos, perdiam todos os direitos: eram o refugo da terra (Arendt, 1990, p. 300).

Segundo nossa autora, “[...] a história contemporânea criou um novo tipo de seres humanos - o tipo que é colocado em campos de concentração por seus inimigos e em campos de internamento por seus amigos" (Arendt, 2016, p. 479). O refugiado incorpora, para Arendt, o descalabro que acontece quando os homens são reduzidos à "mera vida", quando perdem os seus vínculos, “[...] quando não são nada além de seres humanos" (Arendt, 2016, p. 490). Foi isso que ela identificou como resultado da desintegração da Europa e do esfacelamento do império austro-húngaro, otomano e russo, mas também do declínio dos Estados-nacionais. O fim dos impérios significou o aparecimento dos minoritários, dos apátridas e a crise dos Estados-nacionais implicou a desnaturalização de vastos setores da população completamente integrados e assimilados às nações, às suas economias, às suas culturas, aos seus regimes de direitos. Colhemos, assim, em Arendt, a ideia de que o refugiado é o paradigma dos seres humanos em situação de desamparo, vítimas de preconceitos étnicos ou de outro tipo, expulsos da humanidade e em risco de descartabilidade.

Arendt identifica, nessa "atmosfera de desintegração" da Europa, a conjugação da mentalidade burguesa, expansionista e economicista, com o discurso do ódio, racista e antissemita. Diz ela: "As modernas condições do poder, [...] junto com o advento do imperialismo e dos movimentos de unificação étnica, foram fatores que solaparam a estabilidade do sistema europeu de Estados-nações" (Arendt, 1990, p. 303). Em face dessa situação, a cultura revolucionária, igualitária, base da organização dos povos ocidentais modernos, vai sendo substituída pelas ideias raciais e nacionalistas, gerando o ambiente propício à produção não mais da mão de obra barata, mas de uma vastidão de seres humanos descartáveis, condenados ao extermínio. O novo refugiado, o refugiado contemporâneo não é só o desassistido e sem direitos, mas torna-se o "refugo da terra", seres direcionados sistematicamente ao descarte e à morte pelos sistemas econômicos e políticos e indica, ao mesmo tempo, a transformação dos sistemas políticos de ambientes propícios aos vínculos e florescimentos humanos em instâncias produtoras da solidão e do lixo humano.

Nas últimas partes em que aborda o Imperialismo, em "Origens do totalitarismo", Arendt anota as dificuldades por que passa, no final do século XIX e início do XX, o republicanismo revolucionário moderno, constitucionalmente igualitário, em direção ao fim dos direitos, da vigência dos Estados de legalidades excepcionais ou burocrático-gerenciais, onde as decisões jurídicas não obedecem às leis constitucionalmente acordadas, mas ao poder discricionário dos grupos 
e movimentos poderosos. Essa situação começa a furar a organização da comunidade europeia e a atravessar os seus ordenamentos jurídicos. Essa nova categoria do refugiado vai além daquela das pessoas que estão experimentando a condição estrita de refugiado. O outlaw, no sentido aqui atribuído, é todo aquele que está em situação de penúria em razão da carência de pertencimento, seja dos vínculos familiares, econômico-sociais, políticos ou legais. Sem esses vínculos, a vulnerabilidade vital impõe-se e a morte passa a apresentar-se com algo próximo. Sem esses laços, os homens são jogados para fora da humanidade.

Esse contexto fez aparecer o que Arendt chama de paradoxo dos direitos humanos, uma vez que os seres humanos deveriam ter sua dignidade resguardada e estar protegidos pelos direitos humanos pelo fato de serem humanos. No entanto, a autora verifica que, ao contrário, quando estão na condição de simples seres humanos, os homens ficam expostos a todo tipo de vulnerabilidades, uma vez que ser apenas humano, sem a proteção de uma comunidade política, é ser tão somente uma vida no jogo, muitas vezes cruel e mortal, das forças econômicas, sociais e grupais na história contemporânea. Vale dizer, quanto mais um ser humano é sujeito dos direitos humanos, ou seja, é mero ser humano, em mais perigo está incorrendo. "A própria expressão "direitos humanos" - diz Arendt - tornou-se para todos [...] uma prova de idealismo fútil ou de tonta hipocrisia" (Arendt, 1990, p. 302).

Arendt vai abordar essa atmosfera da ruína dos direitos no capítulo " $\mathrm{O}$ declínio do Estado-Nação e o fim dos direitos dos homens", em "Origens do Totalitarismo" (1951). Trata-se de um texto importantíssimo para nossa reflexão, pois conjuga de forma cabal os liames constitutivos da desintegração dos corpos políticos europeus e a submersão da Europa nos tempos sombrios, devorador dos elementos civilizatórios milenarmente construídos e sustentados pela cultura ocidental. Essa perda de elos conduziu ao "tudo é possível" dos regimes totalitários. Nesse escrito, Arendt vai apontando os passos por meio dos quais a inflação, o desemprego, as guerras civis e mundiais vão jogando compactos e enormes grupos humanos numa enorme instabilidade e retirando os seus lugares na terra. Povos sem Estado, povos minoritários, cidadãos de segunda classe, grupos desnaturalizados, até o caso-limite dos povos indeportáveis, que não têm onde ficar, para onde ir ou ser enviados. Nesse caso, sem precedente não era a perda do lar, mas a impossibilidade de encontrar um novo lar, no sentido de família, pátria, Estado. Sob a vigência do sistema de Estado-nação, parcelas

4 Outro momento de ruína política, jurídica e social abordado por Arendt aparece no livro "Crises da República", em que a autora reflete sobre a situação americana contemporânea. Esse livro traz articulações importantes para o nosso assunto, mas, por razões de espaço, será considerado noutro momento, em outro texto. 
enormes de seres humanos vão ficando sem o olhar protetor da comunidade política e da lei. Condenava-se, desse modo, parte da população europeia à posição e estratégias dirigidas aos povos coloniais. Introduziam-se na própria Europa os impiedosos métodos de dominação colonial (Cf. Arendt, 1990, p. 304). Para Arendt, essa é a trilha que leva direto às descartabilidades humanas. Ficava, assim, evidente a incapacidade dos Estados-nacionais europeus de proteger os direitos humanos dos que haviam perdido os seus direitos nacionais. A esses, no melhor dos casos, foi dada uma lei de segunda classe consignada no Tratado das Minorias e chancelada pela Liga das Nações criada naquele período (1919).

Tal como os povos colonizados, esses milhares de europeus sem lugar, sem Estado e sem lei, vagavam de um lado para outro como meros seres vivos. Sem um território para ir, sem uma lei para se proteger, sem um trabalho para garantir a própria sobrevivência, sem uma comunidade para participar, esses povos viviam sem inserção histórica, sem poder produzir, agir, falar e deliberar. Ao mesmo tempo, viam ruir sob seus pés a base dos direitos humanos e de qualquer outro direito, como o direito ao asilo, e tornavam-se caso de polícia, gerenciados pela lógica anônima e burocrática das normas nacionalistas. Esse contexto foi captado muito bem pelos filmes de Charles Chaplin, nos quais o personagem judeu ou refugiado sempre tinha perto de si a companhia tosca, abobalhada e inóspita do policial. Começava, assim, a explicitar-se a ligação entre cidadania e nascimento e a incapacidade de tolerar qualquer oposição. Sem uma posição apropriada na estrutura da lei, os homens sem Estados ficavam à mercê da polícia (Cf. Arendt, 1990, p. 317).

No início do século XX, era divulgado que existiam duas soluções para esses povos: naturalização ou liquidação (cf. Arendt, 1990, p. 306). Já estava em pleno vigor, e jogando um papel central nas relações e comunicações políticas, o ódio. Por isso, preponderou a liquidação, o extermínio, pois o ódio e a desintegração dos vínculos cimentaram a estrada para os campos de concentração. Não havia mais espaço para naturalização. Ao contrário, ocorreram sucessivos decretos de desnaturalização e surgiram, inicialmente, os campos de internamento. Tratavase de um pequeno território com reduzida comunicação com o mundo exterior onde eram depositadas essas pessoas. Logo em seguida, surgiram os campos de extermínio, onde reinava a absoluta ausência da lei e a morte se tornou o destino (cf. Arendt, 1990, p. 302).

Essa lógica começou a instalar-se na Europa, segundo Arendt, a partir do Caso Dreyfus, ocorrido em 1894, na França. A lógica republicana, Ex Parte Populi, da lei igual e imparcialmente disposta para todos, foi substituída pela voz odiosa dos grupos que se digladiavam nas arenas das cidades francesas e europeias. Começou a emergir, nesse momento, a ideia de inimigo objetivo, "criminosos 
sem crimes" (Arendt, 1990, p. 347): grupos e etnias que, independentemente do que fizessem ou falassem, estavam destinadas à morte. É a preponderância política do ódio racial pondo-se como árbitro de quem deve nascer, viver e morrer.

Apesar dessa situação, Arendt não desistiu da ideia de direito e da lei. Ao contrário, verifica a importância de reconstruir o direito e os corpos políticos como condição geradora de ilhas de segurança, espaços do comum e da liberdade política. Sem essas frágeis articulações, os seres humanos ficam completamente à mercê das relações de força, da onipotência policial, da vontade do mais forte, do mais rico ou do mais poderoso e, assim, nenhuma convivência humana institui-se. O direito e a lei foram fragilizados no momento em que foi "[...] consumada a transformação do Estado de instrumento da lei em instrumento da nação; a nação havia conquistado o Estado e o interesse nacional chegou a ter prioridade sobre a lei [...]" (Arendt, 1990, pp. 308-309). No entanto, lembra Arendt, a criação dos Estados-nações coincidiu com o aparecimento dos “[...] governos constitucionais e os Estados-nações sempre haviam representado o domínio da lei e nele se baseavam, em contraste com o domínio da burocracia administrativa e do despotismo - ambos arbitrários" (Arendt, 1990, p. 309).

Trata-se de retomar, em novas bases, o princípio republicano da legalidade, uma vez que

[...] o Estado-nação não pode existir quando o princípio da igualdade perante a lei é quebrado. Sem essa igualdade legal, que originariamente destinava-se a substituir as leis e ordens mais antigas da sociedade feudal, a nação se dissolve numa massa anárquica de indivíduos super e subprivilegiados. [...] Quanto mais clara é a demonstração da sua incapacidade de tratar os apátridas como "pessoas legais", [...] mais difícil é para os Estados resistir à tentação de privar todos os cidadãos da condição legal e dominá-los com uma polícia onipotente (Arendt, 1990, pp. 323-324).

A dificuldade de reconhecer e proteger legalmente os apátridas gerou a brecha para a desproteção legal de todos, inclusive daquelas pessoas reconhecidas como cidadãs. A centralidade da segurança tornou o domínio policial sucedâneo da lei e do direito. Na contramão da visão policialesca do princípio da legalidade, Arendt não almeja enfatizar a força da lei, seu poder de coerção, mas sua capacidade de fundar a vida comum e plural, de viabilizar a ação conjunta, mesmo em situação de conflito, sem implicar a soma zero. Arendt quer evitar a situação paradoxal que ela enxergava como inerente ao surgimento dos direitos dos homens:

Os Direitos do Homem, afinal, haviam sido definidos como "inalienáveis" porque se supunha serem independentes de todos os governos; mas sucedia que, no momento em que os seres humanos deixavam de ter um governo próprio, não restava nenhuma 
autoridade para protegê-los e nenhuma instituição disposta a garanti-los (Arendt, 1990, p. 325).

Trata-se de retomar a ideia revolucionária, moderna e republicana de que todos são iguais perante a lei. Ligar o princípio da legalidade e da fundação dos corpos político à ideia de condição humana é o caminho apontado por nossa autora $^{5}$ e delineado nesse texto de "Origens", antecipando posições que serão aprofundadas posteriormente, principalmente, em "A condição humana". A igualdade, assim compreendida, não é natural, mas resultado do esforço humano. Sobre isso, diz Arendt: "A igualdade, em contraste com tudo que se relaciona à mera existência, não nos é dada, mas resulta da organização humana, porquanto é orientada pelo princípio da justiça" (Arendt, 1990, p. 335). Esse princípio da legalidade atrelado à condição humana é sustentado pelo mundo comum.

O grande perigo - diz Arendt - que advém da existência de pessoas forçadas a viver fora do mundo comum é que são devolvidas, em plena civilização, à sua elementaridade natural, a sua mera diferenciação. Falta-lhes aquela tremenda equalização de diferenças que advém do fato de serem cidadãos de alguma comunidade (Arendt, 1990, p. 335).

O princípio básico que rege a condição humana, segundo Arendt, é de que a pluralidade é a lei da terra. Por um lado, dividimos como seres naturais a ontológica qualidade da diversidade biológica. Traços, cores, tamanhos, etnias, gêneros, espécies formam a rica e plural característica da natureza. Por outro lado, costumes, hábitos, línguas, culturas e leis formam a estrutura que estabelece a condição para aparição plural dos seres humanos no mundo comum. Sem a proteção desse mundo comum, os homens perdem a espontânea capacidade de agir e falar. Assim, constitui-se como desafio aos seres humanos o estabelecimento de leis, corpos políticos e formas de produção que preservem essa riqueza da pluralidade natural e humana. Sem esse compromisso, temos a terra arrasada, o deserto, a solidão e o desamparo corroendo o encanto e a riqueza natural, bem como destruindo a beleza e a riqueza da vida e do mundo humano comum.

Essa tentação à homogeneização da natureza e dos homens fortaleceuse com a modernidade. Tanto a natureza quanto os corpos políticos têm sido objeto da tendência à hybris humana que visa artificializá-la e nivelá-la, a fazer a natureza e o mundo à imagem e semelhança do homem. Essa é a postura

5 Embora não tenha partido do pano de fundo da situação dos refugiados, uma excelente abordagem sobre a relação entre o direito e a condição humana encontramos em "Direito e Política em Hannah Arendt", de Ana Paula Repolês, publicado pela editora Loyola, em 2013. 
típica do humanismo moderno. Do ponto de vista político, isso significa a porta de entrada do ódio e da intolerância nas disputas nos espaços públicos. Cultivam-se, dessa forma, posturas fechadas à comunicação, ao respeito e à convivência com o outro, com o diferente. Enseja-se a criação de um mundo feito à imagem e semelhança de si mesmo, sem ninguém, sem novidade, sem discurso, sem ação. Sobre isso, nossa autora afirma que:

[...] onde quer que uma civilização consiga eliminar ou reduzir ao mínimo o escuro pano de fundo das diferenças, o seu fim será a completa petrificação; será punida, por assim dizer, por haver esquecido que o homem é apenas o senhor, e não o criador do mundo (Arendt, 1990, p. 335).

Dessa forma, o princípio da legalidade em Arendt enseja corrigir as hierarquias, a homogeneização, os privilégios e a violência no interior das comunidades e dar um formato político aos corpos cívicos. Se o atrelamento do Estado moderno à nação gerou o privilégio dos nacionais e produziu as desumanizadas figuras dos refugiados, minoritários, desnacionalizados e apátridas em geral, o restabelecimento do vínculo entre a política e o princípio da legalidade, no sentido arendtiano, abre o caminho para a retomada da igualdade como evidente preponderância da justiça nas relações no interior das comunidades políticas. Se a substituição da lei pela nação era evidente no início do século $\mathrm{XX}$ e, por isso, foi abordada criticamente por Arendt, em outros momentos, a substituição da lei por práticas excepcionais como algo normal em vista do benefício da sociedade, da maioria, dos mais ricos, dos mais fortes também foi criticada pela autora em pauta.

A ligação entre princípio da legalidade, condição humana e pluralidade consigna-se na divisa arendtiana do "direito a ter direitos" e esse é o impacto que o outlaw contemporâneo, o refugiado, vai ter na compreensão da lei e do direito em Arendt. Nessa frase, está assinalada a defesa do direito e da lei, mas não como algo meramente formal, normativo. O sentido do princípio da legalidade não é a obrigação de fazer ou de obedecer, contudo propiciar a efetiva participação das pessoas nos assuntos comuns e fincar o horizonte fundacional dos corpos políticos na pluralidade humana. Sem acesso ao mundo comum, não há equalização; privado da expressão e da ação sobre o mundo comum, o homem torna-se um ser humano em geral, pertencente à raça humana, mero animal, desprovido dos vínculos que o qualificam e podem protegê-lo como ser humano e, assim, torna-se matável. Segundo Arendt, no instante "[...] em que a pessoa se torna ser humano em geral - sem uma profissão, sem uma cidadania, sem uma opinião, sem uma ação pela qual se identifique e se especifique - 
[...] privada de expressão e da ação sobre o mundo comum, perde todo o seu significado" (Arendt, 1990, p. 336).

Essa é a perspectiva que em Arendt visa esclarecer a questão de como foi possível o surgimento dos campos de concentração no centro da Europa ocidental, berço do surgimento da ideia de direitos humanos. O seu problema é pensar qual o lugar destinado aos homens nos corpos políticos, nos modos de produção, nas relações sociais. Sua dificuldade reside em compreender como a Europa pôde propor os direitos humanos e, ao mesmo tempo, permitir os campos de concentração. O ponto de vista de Arendt não é o europeu oficial, mas dos desnacionalizados, dos refugiados, das minorias no interior dos Estados nacionais, os displaced persons, os párias, os outlaws. Sua reflexão não só ajudou a pensar os direitos humanos no interior da ONU, mas também força uma reflexão sobre esses direitos para além do jusnaturalismo e do positivismo jurídico. Se é possível pensar algum vigor na ideia de direitos, isso se dará a partir da aceitação dos limites e até mesmo do fracasso da sua vigência sob a égide dos Estados nacionais. Arendt aponta para uma perspectiva que vai além de uma fundamentação humanista e juspositivista dos direitos que advieram com o estabelecimento dos Estados nacionais. O humanismo transforma-se em humanitarismo na prática e o juspositivismo, na banalização dos direitos humanos e numa proliferação normativa burocrática, suporte para posições ideológicas do Ocidente.

Para Arendt, direitos ou significa direito a ter direitos ou não significa nada. Encaminha, assim, sua ideia de direito e de direitos humanos para uma teoria da cidadania. Essa teoria está delineada no texto de que nos ocupamos aqui e será melhor explicitada em seus textos posteriores. Trata-se não de uma cidadania formal, calcada na origem nacional e na mera formalidade burocrática da lei. Nessa autora, direitos apontam para uma igualização jurídico-política e não apenas jurídico-formal, racial ou territorial. Arendt possui a convicção de que é a igualdade política, a pertença a uma comunidade organizada politicamente e a participação num mundo comum por meio do trabalho, da palavra e da ação que gerará concretamente a proteção e dará suporte real à dignidade humana. Não serão normas jurídicas ou direitos específicos formais que protegerão, de fato, as pessoas do ódio racial ou de classe, mas os vínculos concretos a que as pessoas têm acesso. Essa ideia tanto pode ajudar a fazer a crítica e apontar os limites dos direitos na tradição contratualista e nacional-soberanista quanto, também, do uso ideológico dos direitos humanos para justificar a guerra contra os não ocidentais. No interior dos atuais Estados de direito, os direitos esbarram na aporia da representação, na qual a cidadania é parcial e mitigada. 
Ao ligar direitos à participação política, Arendt calca sua teoria da cidadania na ação e no juízo, na liberdade para agir, falar e trabalhar. Sobre isso diz:

Só percebemos a existência de um direito a ter direitos (e isto significa viver numa estrutura onde se é julgado pelas ações e opiniões) e de um direito de pertencer a algum tipo de comunidade organizada, quando surgiram milhões de pessoas que haviam perdido esses direitos e não podiam recuperá-los devido à nova situação política global (Arendt, 1990, p. 330).

A ação e o juízo apontam uma compreensão dos direitos ligados à capacidade de iniciar, de opinar, de fundar, de agir em conjunto. Ter direitos é ter poder. Em nada podemos comparar Arendt à compreensão consumista, funcionalista dos direitos. Na autora, direito significa a possibilidade concreta de se organizar politicamente, pertencer e decidir a respeito das questões relacionadas ao mundo comum. Sem isso, o direito não passa de mera fantasia ideológica e alienada.

Ao centrar na ação, Arendt faz a crítica à centralidade do trabalho nas sociedades modernas e liga essa centralidade ao processo de biologização, esteio do racismo e da forma burocrática de organização das sociedades em seu tempo. Do mesmo modo, aponta os limites do individualismo liberal burguês que predomina nas nossas sociedades. Contra o formalismo jurídico moderno, a teoria da ação de Arendt critica o representacionismo e propõe como mais importante na fundamentação do poder e das comunidades políticas não o direito formal, mas uma jusphilia, na qual a amizade é entendida não no seu sentido moderno, como partilha de intimidade, mas como possibilidade concreta de escolher livremente o modo de viver e, ao mesmo tempo, pertencer e partilhar o mundo comum. Essa ideia pode ser asseverada em vários escritos seus, mas especialmente em "A condição humana". ${ }^{6}$

Na mesma direção, temos o juízo, o conceito de julgamento em Arendt que é a liberdade de conectar-se à comunidade por meio da opinião. O juízo político indica essa postura de abertura à alteridade, de capacidade de dialogar com os outros nas situações de conflito e divergência nos assuntos da comunidade. Indica que na comunidade, publicamente articulada, reside a instância de deliberação dos assuntos comuns. Esse tema perpassa, também, toda obra de Hannah Arendt, mas aparece especialmente nas "Lições sobre a filosofia política de Kant". A autora diz que o juízo é o outro lado de uma compreensão da atividade política baseada na ideia de ação. O juízo político possui caráter

6 Sobre o tema da amizade em Arendt, cf. de ORTEGA, F. "Para uma política da amizade: Arendt, Derrida, Foucault". Rio de Janeiro: Relume-Dumará, 2000; AGUIAR, O. "A amizade como amor mundi em Hannah Arendt". O que nos faz pensar, Nr. 28, 2011. 
persuasivo, ao contrário do juízo científico, que é determinante, universal e necessário. Está, por isso, mais próximo da opinião, liga-se à ideia de que o cidadão tem completa liberdade de expressão. Pressupõe um espaço público. Ninguém julga para si mesmo. Somente partilhando um mundo comum é que o juízo político faz sentido. Seu modo de validação é retórico-persuasivo, pressupõe a concordância e aquiescência dos outros para obter validade política. Ação sem juízo não é ação política, mas força, violência.

Por último, gostaria de frisar que essa ligação entre direito e política é importante para evidenciar e refletir sobre o lugar do outlaw nessa nova compreensão da organização jurídico-política. Se, na versão moderna, nacionalista e soberanista, é constitutiva do direito e do poder a exclusão, a dominação e a obediência, a versão arendtiana, formada na escola judaica de Bernard Lazare, defensora da tradição do pária consciente, pauta-se na possibilidade de participar do mundo, mas sem se render completamente a ele; da mesma forma, o direito e a cidadania não pressupõem uma completa adesão à sociedade estabelecida, uma assimilação e integração total ao meio social, produtivo, cultural e político em que se vive. Nessa postura, mantêm-se intactas e conjugam-se as potencialidades de resistência, do dissenso e as possibilidades de organização política. Os corpos políticos sustentam, nessa visão, a pluralidade de posições e convicções, no limite da manutenção da autoridade do mundo comum. Uma prática da cidadania e do direito nos moldes pensados por Arendt poderia ser um indício de que podemos acreditar que "o homem não nasceu para morrer, mas para começar".

\section{Referências}

ARENDT, H. "Origens do Totalitarismo". Tradução de Roberto Raposo. São Paulo: Companhia das Letras, 1990.

ARENDT, H. "Escritos Judaicos". Tradução de Thiago Dias Silva et al. São Paulo: Amarilys, 2016.

ARENDT, H. "La tradition cachée. Le juif comme paria”. Paris: Christian Bourgois, 1987. ARENDT, H. "Auschwitz et Jérusalem”. Paris: Deux temps-Tierce, 1991.

ARENDT, H. "A Condição Humana”. Tradução de Roberto Raposo. Revisão técnica de Adriano Correia. Rio de Janeiro: Forense, 2010.

ARENDT, H. "O que é a Política". Tradução de Reinaldo Guarany. Rio de Janeiro: Bertrand Brasil, 1998.

ARENDT, H. "Entre o Passado e Futuro". Tradução de Mauro Barbosa de Almeida. São Paulo: Perspectiva, 1988.

ARENDT, H. "Lições sobre a Filosofia Política de Kant". Tradução de André Duarte. Rio de Janeiro: Relume/Dumará, 1993.

AGUIAR, O. et al. "Filosofia e Direitos Humanos". Fortaleza: Editora UFC, 2006. 
AGUIAR, O. "A amizade como amor mundi em Hannah Arendt". Revista O que nos faz pensar, Rio de Janeiro, Nr. 28, pp. 131-144, 2011.

AGUIAR, O. "Hannah Arendt e o direito I". Revista Argumentos, Fortaleza, Nr. 18, 2017. BENHABIB, S. "The Rights of Others: Aliens, Residents and Citizens". Cambridge and New York: Cambridge University Press, 2004.

BENHABIB, S. "O declínio da soberania ou a emergência de normas cosmopolitanas? Repensando a cidadania em tempos voláteis". Civitas. Porto Alegre, Vol, 12, Nr. 01, pp. 20-46, 2012.

D'ENTRÈVES, M. P. “Hannah Arendt's conception of citizenship”. (pp. 39-166). In: The Political Philosophy of Hannah Arendt. London, New York: Routledge, 1994.

GOLDONI, M.; MCCORKINDALE, C. (org.). "Hannah Arendt and the Law". Oxford: Hart, 2012.

GÜNDOGDU, A. "Rightlessness in an age of rights". New York: Oxford University Press, 2015.

GÜNDOGDU, A. "Perplexities of the rights of man': Arendt on the aporias of human rights". European Journal of Political Theory, Vol. 1, Nr. 11, pp. 4-24, 2011. [Online]. KALYVAS, A. "Democracia constituinte". Lua Nova, São Paulo, Nr. 89, pp. 37-84, 2013. LAFER, C. "A Reconstrução dos direitos humanos". São Paulo: Companhia das Letras, 1991.

ORTEGA, F. "Para uma política da amizade: Arendt, Derrida, Foucault". Rio de Janeiro: Relume Dumará, 2000.

RIBAS, C. M. “Justiça em Tempos sombrios”. Ponta Grossa: Ed. UEPG, 2005.

RIBAS, C. M. "Os direitos humanos no mundo do animal laborans". Argumentos revista de Filosofia da UFC, Fortaleza, Nr. 09, pp. 169-180, 2013.

TORRES, A. P. R. "Direito e política em Hannah Arendt”. São Paulo: Loyola, 2013.

VOLK, C. "Arendtian Constitutionalism". Oxford: Hart, 2015. 